\section{JTI}

JOURNAL OF

TRAUMA AND INJURY

\title{
Limited Incisional Drainage and Negative-Pressure Wound Therapy in an Acute Morel-Lavallée Lesion
}

\author{
Eui-Sung Choi, M.D., Jae-Young Yang, M.D., Byung-Hyun Ahn, M.D. \\ Department of Orthopaedic Surgery, Chungbuk National University Hospital, Cheongju, \\ Korea
}

Received: August 10, 2020

Revised: September 22, 2020

Accepted: October 13, 2020

\section{Correspondence to}

\section{Jae Young Yang, M.D.}

Department of Orthopaedic Surgery, Chungbuk National University Hospital,

776 1sunhwan-ro, Seowon-gu, Cheongju 28644, Korea

Tel: +82-43-269-6077

Fax: $+82-43-274-8719$

E-mail: hahayourdead@naver.com

\begin{abstract}
A Morel-Lavallée lesion is a post-traumatic closed degloving soft tissue injury after blunt trauma. Infection and skin necrosis frequently occur if it is not treated properly in the early stages. However, there is no clearly established treatment algorithm. In the acute stage, it is mainly treated with aspiration, simple compression, and incisional drainage. In the chronic stage, sclerotherapy is usually performed. If skin necrosis develops, the necrotic tissue is resected and a skin graft is needed. We describe a case of acute Morel-Lavallée lesion in the buttock region that was treated with limited incisional drainage and negative-pressure wound therapy, and also present a review of the literature.
\end{abstract}

Keywords: Morel-Lavallée lesion; Negative-pressure wound therapy; Limited incision

\section{INTRODUCTION}

In 1863, a French physician named Victor-Auguste-François Morel-Lavallée first described a unique posttraumatic fluid collection that developed in a patient after trauma [1]. Letunnel and Judet named the accumulation of blood or plasma resulting from a degloving injury between the fascia and the subcutaneous layer after trauma as the Morel-Lavallée lesion in 1993 [2]. Morel-Lavallée lesions can occur in any part of the body, but are most frequently encountered in the buttock region; nonetheless, it is a rare condition that occurs in about $1.7 \%$ of patients after pelvic fractures [3]. We report a case of an acute Morel-Lavallée lesion in the buttock region that was successfully treated with limited incisional drainage and negative-pressure wound therapy. 


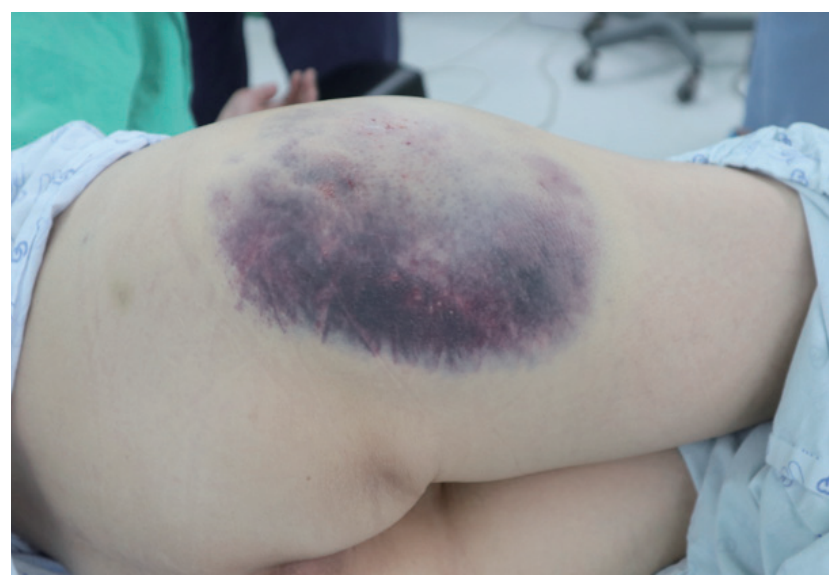

Fig. 1. A bluish color change on the right buttock measuring $25 \times 15 \mathrm{~cm}$.
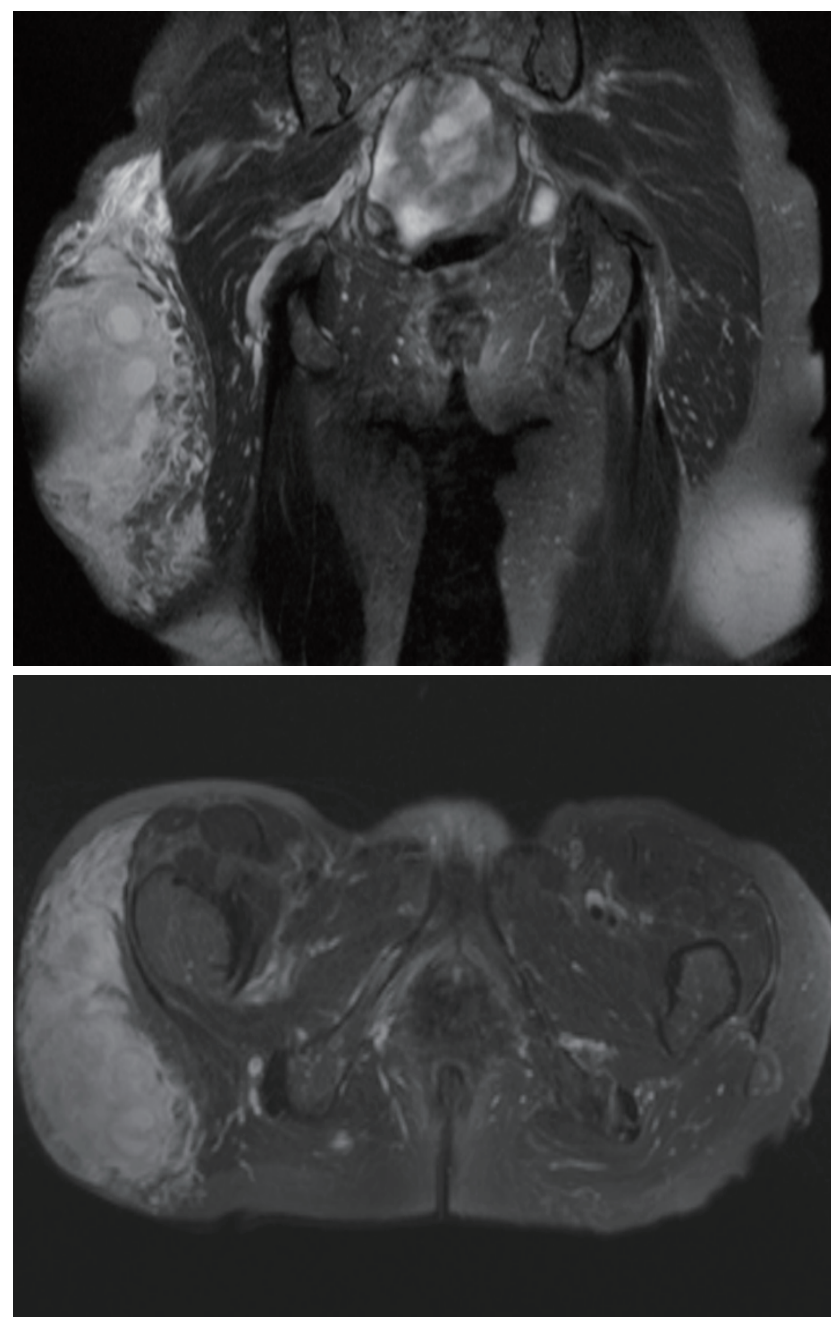

Fig. 2. Magnetic resonance imaging (upper: coronal view, lower: axial view) showing a large amount of fluid collection between the subcutaneous tissue and fascia layer in the right buttock area.

\section{CASE REPORT}

A 53-year-old woman was referred to the emergency room via a local hospital with pain in the right buttock by a pedestrian accident 8 hours ago. On physical examination, she was noted to have a skin color change on the right buttock measuring $25 \times 15 \mathrm{~cm}$ and tenderness with fluctuation (Fig. 1).

No fracture was found on the initial X-ray examination. Magnetic resonance imaging (MRI) was performed to
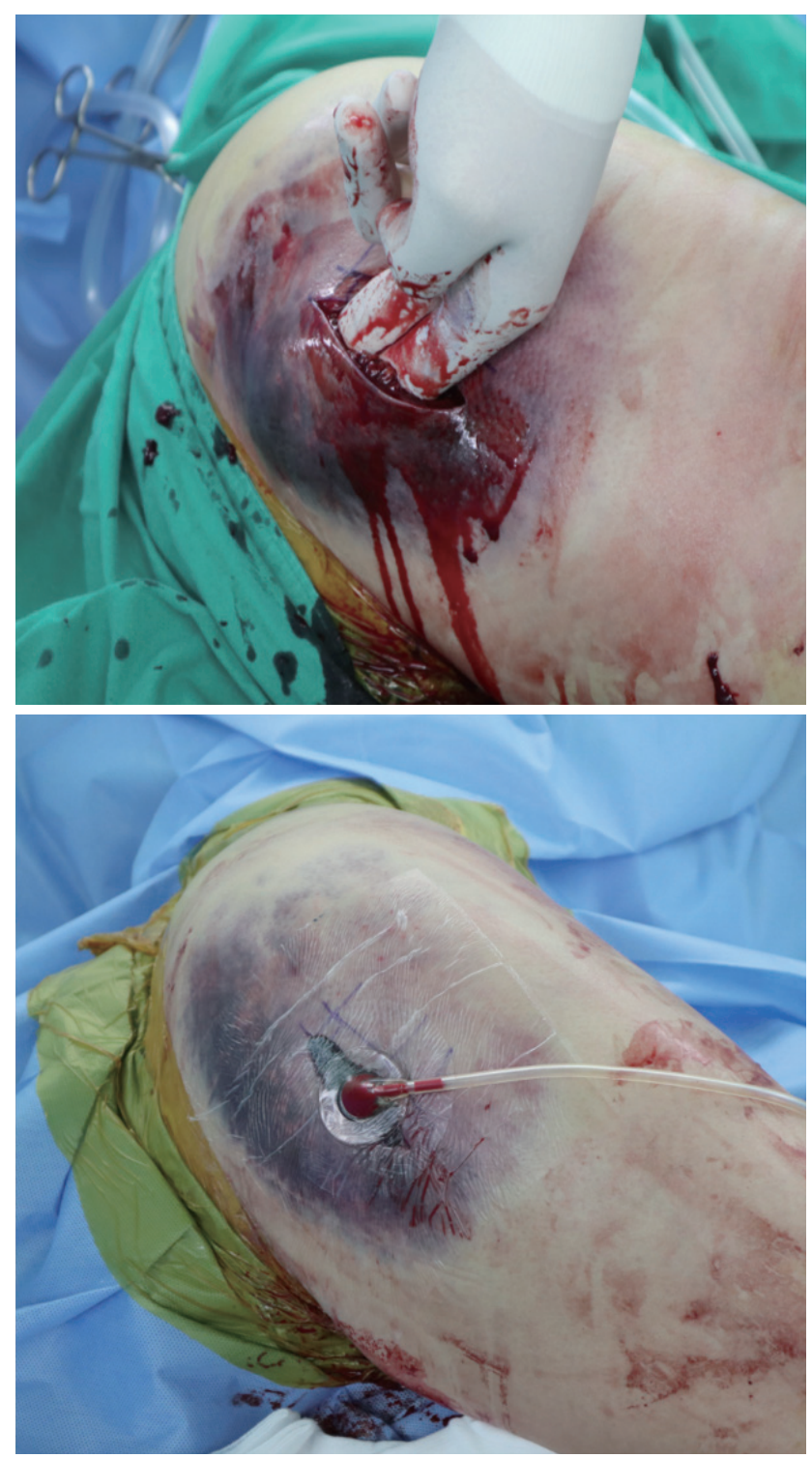

Fig. 3. After incision and drainage, negative-pressure wound therapy was applied to the incision area. 
determine the cause of the fluctuation; in particular, we sought to ascertain whether it was a simple hematoma or a Morel-Lavallée lesion. MRI revealed a wide range of fluid collection measuring $25 \times 15 \times 10 \mathrm{~cm}$ between the fascia and subcutaneous layers (Fig. 2). Therefore, we diagnosed it as a Morel-Lavallée lesion and performed incision and drainage in the operating room under local anesthesia. A 7-cm longitudinal incision was performed where the swelling was most severe. Necrotic tissue was not observed, because surgery was performed immediately after the injury. Serous fluid containing a large amount
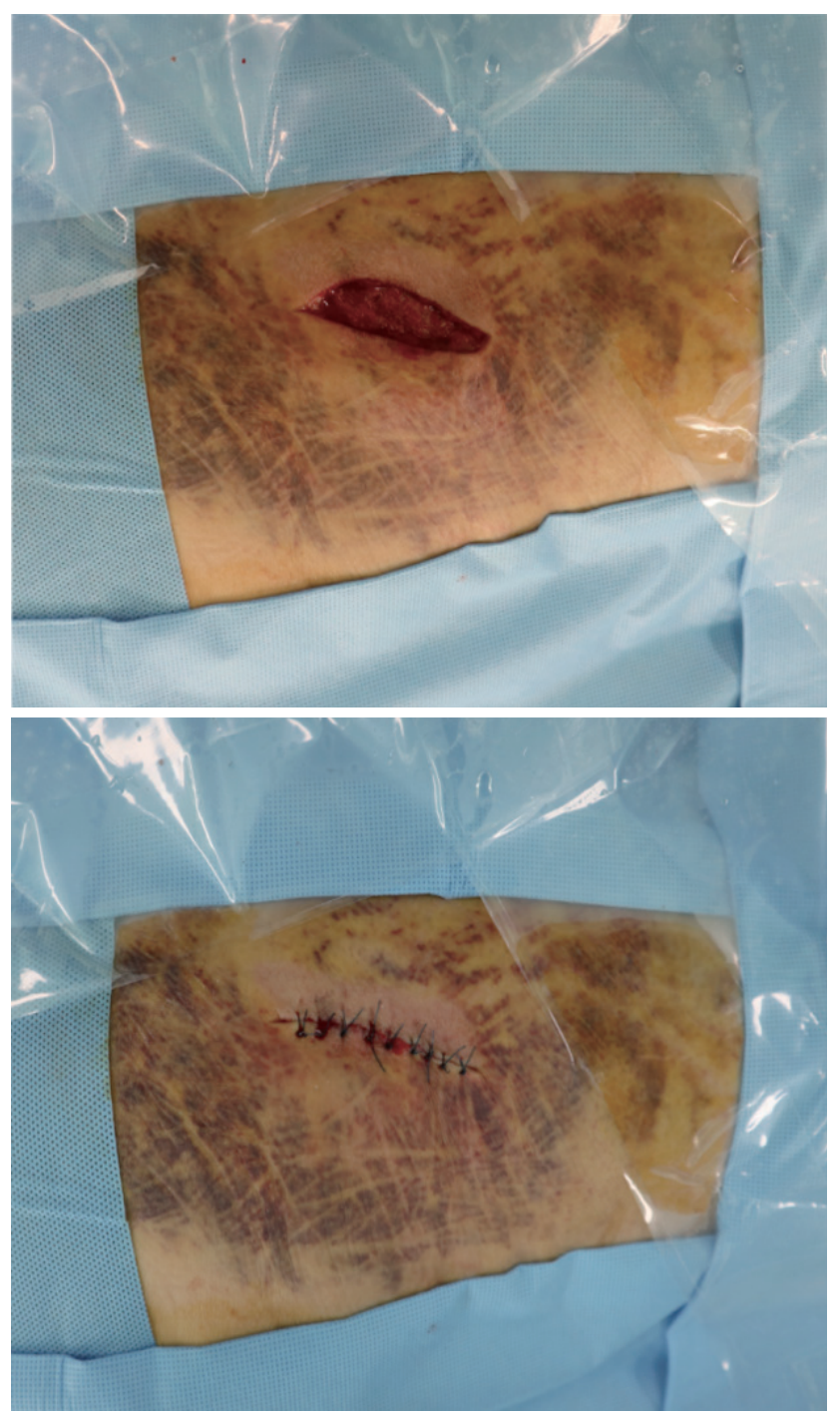

Fig. 4. One week after surgery, the negative-pressure wound therapy device was removed and secondary repair was performed. of blood flowed through the incision window. Devitalized fatty tissue was removed using a curette via the incision window and the area was washed with normal saline $(10 \mathrm{~L})$.

Subsequently, a negative-pressure wound therapy device (V.A.C. ${ }^{\circledR}$, Kinetic Concepts Inc., San Antonio, TX, USA) was applied to the incision window (Fig. 3). One week after the operation, we removed the negative-pressure device, confirmed that the subcutaneous tissue had adhered to the fascia, and performed secondary repair (Fig. 4). Two weeks after the operation, the stitches were removed at the outpatient clinic, the skin color changes had improved (Fig. 5), and no fluid collection remained on the follow-up ultrasound examination.

\section{DISCUSSION}

An acute Morel-Lavallée lesion can be treated conservatively with only simple compression in cases of small fluid collections; however, infection is common in cases of large fluid collections, and necrosis of the skin degloved from the fascia is also common [4]. There is no clearly established treatment algorithm. Seo et al. [5] and Kumar et al. [6] suggested the quilting technique for fixing degloved subcutaneous tissue to the fascia layer, and Alexandris et al. [7] proposed using hip gradient compression socks to

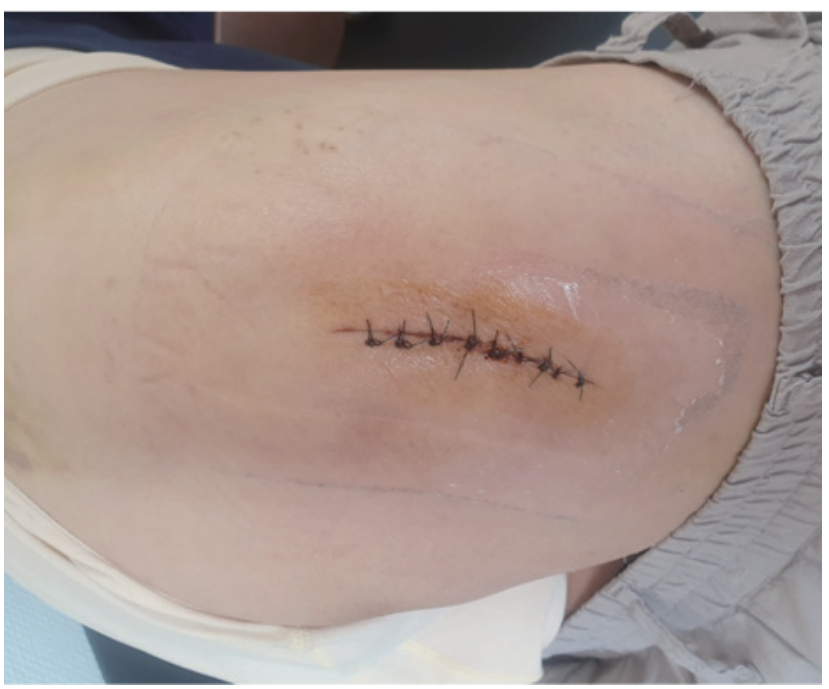

Fig. 5. Two weeks after the operation, the previous skin color had improved. 
improve the compression efficiency. In this case, incisional drainage was performed because the fluid collection was large. Negative-pressure wound therapy was applied for the following reasons.

First, we wanted to increase the efficiency of fixation between the subcutaneous tissue and the fascia layer. Unlike the extremities, it is difficult to wrap a compression bandage around the buttock. In this situation, where the possibility of skin necrosis was high due to color change, we applied a negative-pressure system to effectively fix the subcutaneous tissue to the fascia layer. Second, we tried to avoid infection. In Morel-Lavallée lesions, infection is prone to occur in the fluid collection; this is a particular concern for lesions in the buttock region, which is vulnerable to infection after incisional drainage and a simple compression bandage due to its proximity to the anus and genitalia. Therefore, we tried to reduce the possibility of infection by applying a negative-pressure device to make the lesion a closed space. Third, NPWT can easily absorb a large amount of fluid under constant pressure. Jackson-Pratt drains and Hemovac systems are commonly used after surgery, but these systems have the disadvantage of the tube often falling out or becoming clogged; thus, these systems exert a small negative pressure on the lesion, and the pressure is not constant. Instead, the drain tubes used for negative-pressure wound therapy are thicker than those used in the Jackson-Pratt or Hemovac system, so they are less likely to become clogged and do not easily fall out. Furthermore, the pressure on the lesion can be adjusted easily, which can increase the fixing force mentioned above. As a disadvantage, negative-pressure wound therapy is more expensive than other treatment strategies, and the volume of the negative-pressure device is large, which may place a relative limitation on ambulation.

Malagelada et al. [8] treated acute Morel-Lavallée lesion using finger-shaped foam with negative-pressure wound therapy. The finger-shaped foam was expected to effectively absorb fluid from the lesion. However, it was expected that the lesion will recur frequently because dead space occurs in the finger area during the process of removing the foam. In contrast, in our case, we expected recurrence to be less likely because we were able to suture the incision window after confirming that there was no dead space.

In this case, the patient already underwent imaging tests, including MRI, at a local hospital and then presented to Chungbuk National University Hospital. The X-ray examination first confirmed the absence of a fracture and then MRI was performed. MRI is known to be better than CT for identifying the types, characteristics, and age of lesions [9].

We successfully treated an acute Morel-Lavallée lesion accompanied by a large amount of fluid collection at the buttock region with limited incisional drainage and negative- pressure wound therapy. It is expected that limited incisional drainage and negative- pressure wound therapy will be a good option to treat acute Morel-Lavallée lesions.

\section{REFERENCES}

1. Morel-Lavallée VAL. Decollements traumatiques de la peau et des couches sous jacentes. Arch Gen Med 1863;1:20-38, 172-200, 300-32.

2. Letournel E, Judet R. Fractures of the acetabulum. 2nd ed. Berlin:Springer Verlag; 1993.

3. Tseng S, Tornetta P 3rd. Percutaneous management of Morel-Lavallee lesions. J Bone Joint Surg Am 2006;88:92-6.

4. Greenhill D, Haydel C, Rehman S. Management of the Morel-Lavallée Lesion. Orthop Clin North Am 2016;47:115-25.

5. Seo BF, Kang IS, Jeong YJ, Moon SH. A huge Morel-Lavallée lesion treated using a quilting suture method: a case report and review of the literature. Int J Low Extrem Wounds 2014;13:14751.

6. Kumar G, Pandiyan A, Theruvil B. Percutaneous quilting technique for the treatment of Morel-Lavallée lesion. Indian J Orthop 2020;54:580-6.

7. Alexandris A, Alexandropoulos C, Goulas V, Tsourvakas S. Morel-lavallée lesions: our treatment experience. MOJ Orthop Rheumatol 2015;2:178-79.

8. Malagelada F, König TC, Bates P. Combination of a drainage tube and fenestrated topical negative-pressure device for the management of Morel-Lavallée lesions. Ann R Coll Surg Engl 2016;98:341-2.

9. Scolaro JA, Chao T, Zamorano DP. The Morel-Lavallée lesion: diagnosis and management. J Am Acad Orthop Surg 2016;24:667-72. 